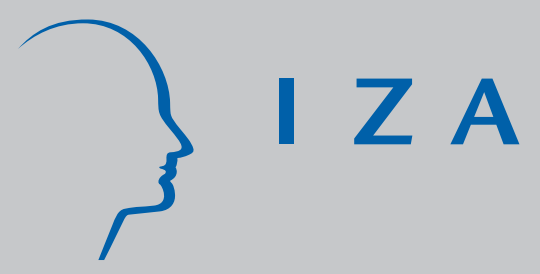

IZADP No. 3554

\title{
Social Interactions and the Salience of Social Identity
}

Kendra N. McLeish

Robert J. Oxoby

J une 2008 


\title{
Social Interactions and the Salience of Social Identity
}

\author{
Kendra N. McLeish \\ University of Calgary
}

Robert J. Oxoby

University of Calgary

and IZA

\section{Discussion Paper No. 3554 \\ June 2008}

\author{
IZA \\ P.O. Box 7240 \\ 53072 Bonn \\ Germany \\ Phone: +49-228-3894-0 \\ Fax: +49-228-3894-180 \\ E-mail: iza@iza.org
}

Any opinions expressed here are those of the author(s) and not those of IZA. Research published in this series may include views on policy, but the institute itself takes no institutional policy positions.

The Institute for the Study of Labor (IZA) in Bonn is a local and virtual international research center and a place of communication between science, politics and business. IZA is an independent nonprofit organization supported by Deutsche Post World Net. The center is associated with the University of Bonn and offers a stimulating research environment through its international network, workshops and conferences, data service, project support, research visits and doctoral program. IZA engages in (i) original and internationally competitive research in all fields of labor economics, (ii) development of policy concepts, and (iii) dissemination of research results and concepts to the interested public.

IZA Discussion Papers often represent preliminary work and are circulated to encourage discussion. Citation of such a paper should account for its provisional character. A revised version may be available directly from the author. 
IZA Discussion Paper No. 3554

June 2008

\section{ABSTRACT}

\section{Social Interactions and the Salience of Social Identity}

In this paper, we explore the effect of identity salience on behavior in a simple social interaction. Specifically, we compare behavior in a ultimatum game across three treatments: priming subjects with a shared identity, priming subjects with an identity distinct from those with whom they will interact, and priming subjects with no particular identity. We find that subjects are most cooperative in the identity-priming treatment and least cooperative in the distinctiveness-priming treatment. Similarly, subjects reveal the highest demands in the identity-priming treatment and the lowest demands in the distinctiveness-priming treatment. We discuss the implications of these results with respect to literature on organizational identity.

JEL Classification: $\quad$ C92, D64, M52

Keywords: identity, experiments, bargaining

Corresponding author:

Robert J. Oxoby

Department of Economics

University of Calgary

2500 University Drive NW

Calgary, Alberta T2N 1N4

Canada

E-mail: oxoby@ucalgary.ca

* Financial support was provided by the Canadian Institute for Advanced Research and the Social Sciences and Humanities Research Council of Canada. 


\section{Introduction}

Each individual has any number of identities. These may include one's ethnic identity, gender identity, corporate identity, or national identity. Past research has shown that each of these identities can be more or less salient at any moment of time and the relative salience of different identities can significantly affect behavior (Akerlof and Kranton, 2000, 2004). Experiments have shown that priming certain pre-existing identities in individuals can affect tasks such as exam performance (Steele and Aronson, 1995; Spencer et al., 1999). For example, Shih et al. (1999) shows that when a math test was administered to Asian-American women primed with either their ethnic identity or their gender identity, they performed more or less well, respectively. As well, Yopyk and Prentice (2005) show that student-athletes primed with either their student or athlete identity performed more or less well, respectively, on a math exam.

This paper focuses on uncovering how priming identity affects behavior in a simple social interaction. Specifically, we are interested in a social interaction as represented by an ultimatum game. In the ultimatum game a Proposer receives an endowment and must decide how much to offer a Responder. If the Responder accepts the offer, both parties receive the agreed-upon amounts. If the Responder rejects the offer, both parties receive nothing. Thus, behavior in the ultimatum game can serve as a barometer for cooperativeness and negative reciprocity wherein offers can be seen as signs of cooperation or generosity, and accept/reject decisions can help identify negative reciprocity or demandingness. ${ }^{1}$ In this paper, we are interested in the relationship between the salience of an individual's identity and their behavior in the ultimatum game. An understanding of the relationship between cooperativeness or demandingness and an individual's identity will yield insights into the underlying reasons for the documented reductions in public goods in the presence of population heterogeneity (e.g., Alesina et al., 1999; Alesina and Ferrara, 2000).

With respect to motivating shared or distinct identities, past research has shown that identity is notoriously difficult to create in the laboratory (see Eckel and Grossman, 2005; Solow and Kirkwood, 2002). Therefore, we take the approach of increasing

\footnotetext{
${ }^{1}$ In this paper, we will define cooperation as having joint concern for the outcomes oneself and another, with higher offers reflecting more cooperation. Note that cooperative behavior in this context does not require reciprocation on the part of another individual: Only one individual in the game has the opportunity to extend and offer.
} 
the salience of an individual's existing identity in order to motivate behaviors such as cooperation. To our knowledge, while other studies have explored the effects of salience on task performance (Yopyk and Prentice, 2005; Spencer et al., 1999), no study has approached the problem of how the salience of existing identity may affect social interactions. As such, this paper adds to the literature by providing information on how priming identity affects a social interaction.

In order to incorporate identity-priming into an experiment, we led participants through a brief identity-priming task along the lines of those used in Yopyk and Prentice (2005) before having them play a bargaining game. One can think of the behaviors exhibited in an ultimatum game as being influenced by concepts of identity. That is, past research has shown that group identity can have an effect on cooperation (McLeish and Oxoby, 2007; Wit and Wilke, 1992), reciprocity (McLeish and Oxoby, 2007; Stroebe et al., 2005), and negotiations (Kramer et al., 1993). In Wit and Wilke (1992), cooperation in simple games was higher among in-group pairs, simply as a result of random group categorization. In Stroebe et al. (2005), researchers found evidence that, under certain conditions, participants expected in-group members to reciprocate more than out-group members, and so participants tended to favor their in-group. Similarly, in McLeish and Oxoby (2007), higher degrees of cooperation were found between in-group pairs, as well as higher degrees of negative reciprocity (i.e. punishment) in response to unfair behavior.

Along the lines of these studies, we see differing degrees of cooperation and negative reciprocity across treatments following our manipulation of the salience of different identities. We find that subjects are most cooperative with in-group members after a shared social identity has been primed, and least cooperative after an identity distinct from the shared social identity has been primed. Similarly, subjects exhibit the highest demands after a shared social identity has been primed and the lowest demands after a distinct identity has been primed.

The results of our experiments have important implications for our understanding of identity in organizations. Akerlof and Kranton (2005) discusses the extent to which and employees identification with her employer (or lack thereof) can have significant effects in mitigating (or aggravating) problems associated with incomplete contracting and unobservability. Indeed, if employees identify with their employer or their organization, they are less likely to engage in shirking or sabotage in the workplace. For 
example, when an organization promotes a positive identity, employees internalize this and exhibit more cooperation and citizenship (Dutton et al., 1994). Further, when the identity of the organization is more salient (for example, through more contact with the organization, longer tenure, etc.), this effect is increased. In the context of our experiment, a shared identity results in greater cooperation as manifest by larger offers in ultimatum bargaining. However, Akerlof and Kranton (2005) also discusses how an identity which is distinct (indeed, contrary) to that of the employer may result in a worker damaging property or shirking in a manner to reclaim an identity which distinguishes the individual from her apparent identity as an employee. In our experiment, we observe lower offers in ultimatum bargaining when individuals are primed with distinct identities. While this is in line with the arguments in Akerlof and Kranton (2005), we also identify a potential cost associated with shared identity. In our experiments we find when individuals share a (positive) identity, respnders in ultimatum bargaining display greater demandingness vis a vis a willingness to reject larger offers than no identity if shared. This suggests that, in the context of an organization, a strong shared identity may manifest itself via greater negative reciprocity. Thus, a shared identity may result in greater sabotage or shirking in contexts where individuals view themselves as being treated unfairly by an employer or other employees with whom they share an organizational identity.

\section{Related Literature}

There is substantial evidence that priming individuals' identities can affect task performance. One such example is the literature on stereotype threat: As discussed above, students who are primed with identities which are typically associated with performing less well on a task tend to conform to the expectation and indeed perform less well. Other examples in the literature show that African Americans primed with their ethnic identity performed less well on an exam (Steele and Aronson, 1995), and women primed with their gender identity performed less well on a math test (Spencer et al., 1999).

The stereotype activation literature comes with at least one qualification: Blatant and subtle stereotype priming may not have similar effects. When stereotypes are subtly primed (Asian-American students completed a survey designed to increase ethnic 
saliency), subjects performed better on a subsequent test, while when stereotypes are blantantly primed (Asian-American students completed a stereotyping questionnaire), subjects' performance is not affected (Shih et al., 2002). On the other hand, when subjects who are not the target of the priming (e.g., non-Asian students) are exposed to the blatant priming, performance is affected, while exposure to subtle priming has no such affect.

There is also evidence that priming identities affect affect behaviors other than task performance. Benjamin et al. (2008) reports the results of priming Asian-American ethnic identity and African-American ethnic identity. ${ }^{2}$ When ethnic identity is primed, Asian-Americans exhibit more patience (i.e. have lower discount rates), and (nonimmigrant) African-Americans exhibit more risk-aversion. In Bargh et al. (1996), there is evidence that priming an elderly stereotype (through the use of a scrambledsentence activity incorporating words relevant to an elderly stereotype, but careful to omit words referring to slowness) caused undergraduate participants to walk more slowly as they left the experiment. The authors also report the results of an experiment demonstrating that priming an African-American stereotype (through subliminal pictures being flashed on a computer screen as a subject is working on a tedious task) caused non-African-American participants to react with more hostility to a computer error.

Research in both psychology and economics literature has demonstrated that social identity can affect simple social interactions. As noted above, identity has been shown to motivate cooperation, reciprocity, and negotiations, but also attitude formation and polarization (Mackie, 1986), and the differential treatment of in-group and out-group members (Bernhard et al., 2006; Durlauf, 1999; Gerber, 1998; Wann and Grieve, 2005). Experimentally, simple games have been used in the study of group identity and results have shown individuals to exhibit more cooperative behavior to in-group members, and punish in-group members more for uncooperative behavior (Goette et al., 2006; Bernhard et al., 2006; McLeish and Oxoby, 2007). Higher rates of cooperation and more negative reciprocity between in-group members has even been proposed by the

\footnotetext{
${ }^{2}$ In the Asian-American study, identities were primed through the use of a "background questionnaire", using questions regarding the languages used by a participant's parents and grandparents, the number of generations a participant's family has lived in the U.S., etc. In the African-American study, identities were primed with a similar questionnaire, however, many of the questions centered around preferences over a roommate's race.
} 
theoretical literature: Benabou and Tirole (2006) and Akerlof and Kranton (2000) propose that the violation of in-group norms by in-group members can be seen as a threat to the identity of the group. As such, individuals are motivated to buoy up the value of the group identity by punishing the offender.

Although identity affects social interactions, past research in economics has found it challenging to establish an artificial identity in the laboratory. For example, Wit and Wilke (1992) establish group categorization by giving groups a common fate: a $50 \%$ chance that each individual would be paid (the personal categorization treatment) or a $50 \%$ chance the group would be paid (the group categorization treatment). While the proportion of cooperative behavior was higher in the group categorization treatment, the difference between the two treatments was not great ( $68 \%$ vs. $57 \%$ ). In the same vein of research, Solow and Kirkwood (2002) used three treatments: a stranger treatment, a treatment where groups worked together on a questionnaire, and a treatment using participants from a common community (e.g. the school's marching band). Only the treatment using participants from the common community showed significant differences in behavior. In Eckel and Grossman (2005) the only successful identity-motivating treatment in which behavioral differences were identified was that in which group members worked together on an initial task.

\section{Experiment and Hypotheses}

In our experiment, participants were provided with a piece of paper and asked to write for 10 minutes on a treatment-specific topic. ${ }^{3}$ After the 10 minute period, participants sealed the paper inside an unmarked envelope and the envelopes were collected by the experimenter.

The treatments were implemented through manipulation of the 10-minute writing period. In the Identity-Prime (IP) treatment, we attempted to increase the salience of a shared identity, that of a student at our university: students were asked to write about a recent positive experience with their fellow students. In our DistinctivenessPrime (DP) treatment we attempted to increase the salience of an identity distinct from our university's: students were asked to write about a recent positive experience with people other than fellow students. In the No-Prime (NP; control) treatment,

\footnotetext{
${ }^{3}$ Sample instructions are presented in appendix A.
} 


\title{
Treatment Name Description
}

\begin{abstract}
Identity-Prime Participants were asked to write about a recent positive experience in which they felt connected to other students at our university, recalling how they felt before, during, and after the experience. The instructions emphasized focusing on how the experience made them feel as a student at our university.
\end{abstract}

Distinctiveness-Prime Participants were asked to write about a recent positive experience outside the university with individuals who were not students at our university, recalling how they felt before, during, and after the experience. The instructions emphasized focusing on how the experience made them feel as individuals.

No-Prime (control) Participants were asked to write out detailed directions on how to get from their dorm room or parking space to the computer lab in which the experiment was taking place.

Table 1: Details of Treatments

students were asked to write out detailed directions from their dorm room or parking space to the laboratory where the experiment was being conducted. This treatment was designed to not affect the salience of anything identity-related. Specific details about each of the treatments are listed in Table 1. In sum, the IP and DP treatments bring attention to either shared or distinct identities. We propose that this identity is salient when engaging in the following stage of the experiment.

After the 10-minute writing period, participants engaged in an ultimatum game. A typical ultimatum game proceeds as follows: In the role of Proposer, the participant receives $\$ 10$ and decides how much of that amount he wishes to allocate to the Responder. The Proposer's offer is then extended to the Responder, and the Responder 
decides to accept or reject the offer. If the Responder accepts the offer, each participant receives the agreed upon amounts, while if the Responder rejects the offer, each participant receives nothing. In the literature, ultimatum game results are consistent, and robust to variation in the conditions of the game (e.g. the amount of money initially allocated to the Proposer; see Camerer, 2003). Proposers offer, on average, about $30-40 \%$ of their endowment, and these offers are typically accepted, while offers below 20\% have about a 50-50 chance of getting rejected.

In this experiment, we chose to conduct the ultimatum game using a method similar to the strategy vector method (i.e. participants decide on the choices they would make in either role before the roles are assigned; see Oxoby and McLeish, 2004). ${ }^{4}$ Participants were informed that they would be randomly and anonymously matched over the computer network with another participant, and one of them would be assigned the role of Proposer and the other would be assigned the role of Responder. However, before receiving these assignments, they were to report the choices they would make in either role (i.e., offer extended in role of Proposer; accept/reject decisions for each possible offer in the role of Responder). Participants were then grouped into pairs, put in the role of either Proposer or Responder, and had their corresponding choices implemented. This method of eliciting responses in the ultimatum game provides us with the benefit of a larger number of observations for potential offers and potential minimum acceptable offers. Further, since it has been shown that behavior resulting from the use of this method is not significantly different from behavior in a sequential decision method ultimatum game (?), the credibility of our results is not compromised. That is, potential offers are equivalent to actual offers, and potential minimum acceptable offers are equivalent to actual minimum acceptable offers. Participants made choices in only one ultimatum game, after which they were paid anonymously and were allowed to leave.

\subsection{Hypotheses}

Given our design, we are able to test several hypotheses regarding the effects of priming identity on ultimatum bargaining. First, as mentioned above, research has shown that

\footnotetext{
${ }^{4}$ Our method is slightly different than the strategy vector method since participants are asked to make choices in both roles. Conceivably, this may lead subjects to be more strategically-minded than when just placed in one role.
} 
sharing an identity leads to greater cooperation (see McLeish and Oxoby, 2007; Wit and Wilke, 1992). ${ }^{5}$ It follows that priming identity (vs. not priming identity or priming distinctiveness) will have similar effects on cooperation in our experiment, as measured through Proposers' offers.

Hypothesis 1 (Potential) offers in the Identity-Priming treatment will be higher than those in the Distinctiveness-Priming treatment.

The Responder's decision allows us to gain insight into reciprocity, preferences over fairness, or demandingness. Information on demandingness is contained in the Responders' minimum acceptable offer (MAO; the lowest offer a Responder indicates she would accept). The higher the MAO, the higher the offer must be for the Responder not to choose to engage in negative reciprocity (i.e. choose to 'reject').

Identity has been shown to have an effect on reciprocity (see McLeish and Oxoby, 2007; Stroebe et al., 2005), in that individuals engage in higher degrees of negative reciprocity with those whom they identify. Further, as mentioned above, theoretical research into identity predicts higher rates of negative reciprocity within the in-group as a response to the violation of in-group norms (Benabou and Tirole, 2006; Akerlof and Kranton, 2000). Essentially, a violation of an in-group norm is seen as a threat to identity, and individuals are therefore motivated to act out in order to protect the value of their identity.

Hypothesis 2 (Potential) minimum acceptable offers in the Identity-Priming treatments will be higher than those in the Distinctiveness-Priming treatment.

\section{Results and Analysis}

A total of 128 participants, recruited from the student body at our university, participated in this experiment. The ultimatum game portion of the experiment was programmed using Fischbacher (2007).

\footnotetext{
${ }^{5}$ Note that identity and cooperation may be positively correlated not because cooperation follows directly from identity but because there exists social norms prescribing higher degrees of cooperation to in-group members. Thus, the social norm governing in-group interactions may cause greater cooperation because (i) an individual wishes to adhere to the social norm, and/or (i) an individual believes the Responder will have higher expectations of an offer and thus a higher minimum acceptable offer (MAO).
} 
First, we concentrate on participants' offers. Recall that since the experiment was run using the strategy method, we have information on what each participant would have offered if they were put in the role of Proposer (i.e. potential offers). Mean offers by treatment are reported in Table 2. Mean offers across treatments vary from a low of $\$ 3.05$ in the DP treatment to a high of $\$ 3.86$ in the IP treatment. The cumulative distributions of offers, by single treatment, are shown in Figure 1, and the frequencies of offers, by treatment, are shown in Figure 2. Our results directionally support Hypothesis 1: The IP treatment tends to have higher offers, the DP treatment tends to have lower offers, and the offers in the NP treatment are somewhere in-between.

Table 2: Mean Offers, by Treatment

\begin{tabular}{lccc}
\hline \hline Treatment & N & Mean Offer & Std. Err. \\
\hline & & & \\
Identity-Prime & 42 & 3.86 & 1.16 \\
Distinctiveness-Prime & 42 & 3.05 & 1.56 \\
No-Prime & 44 & 3.61 & 1.35 \\
\hline
\end{tabular}

For a more robust investigation, we ran one-tailed $t$-tests of statistical differences in mean offers between treatments. ${ }^{6}$ The $p$-values from each pairwise test are reported in Table 3. Offers in IP are significantly higher than offers in DP, but not significantly different from the NP treatment. DP delivers significantly different results from both other treatments: Offers are significantly less than IP and NP. These results support hypothesis 1: Offers are significantly higher when participants are primed with a shared identity than when participants are primed with a distinct identity.

Given our elicitation method, we have data on each participant's minimum acceptable offer (MAO). Mean MAOs for the five treatments are reported in Table 4 with the cummulative and frequency distributions presented in Figures 3 and 4 . Over all treatments, mean MAOs range from a low of $\$ 2.40$ in the DP treatment through to a high of $\$ 3.00$ in the IP treatment. Again, these results suggest the data is directionally consistent with Hypothesis 2: More participants in the IP treatment choose higher MAOs, those in the DP treatment choose lower MAOs, and MAOs in the NP

\footnotetext{
${ }^{6}$ We chose to use $t$-tests for this analysis because our data met the requirements for a $t$-test and the $t$-test gives us more precise results than a non-parametric test.
} 


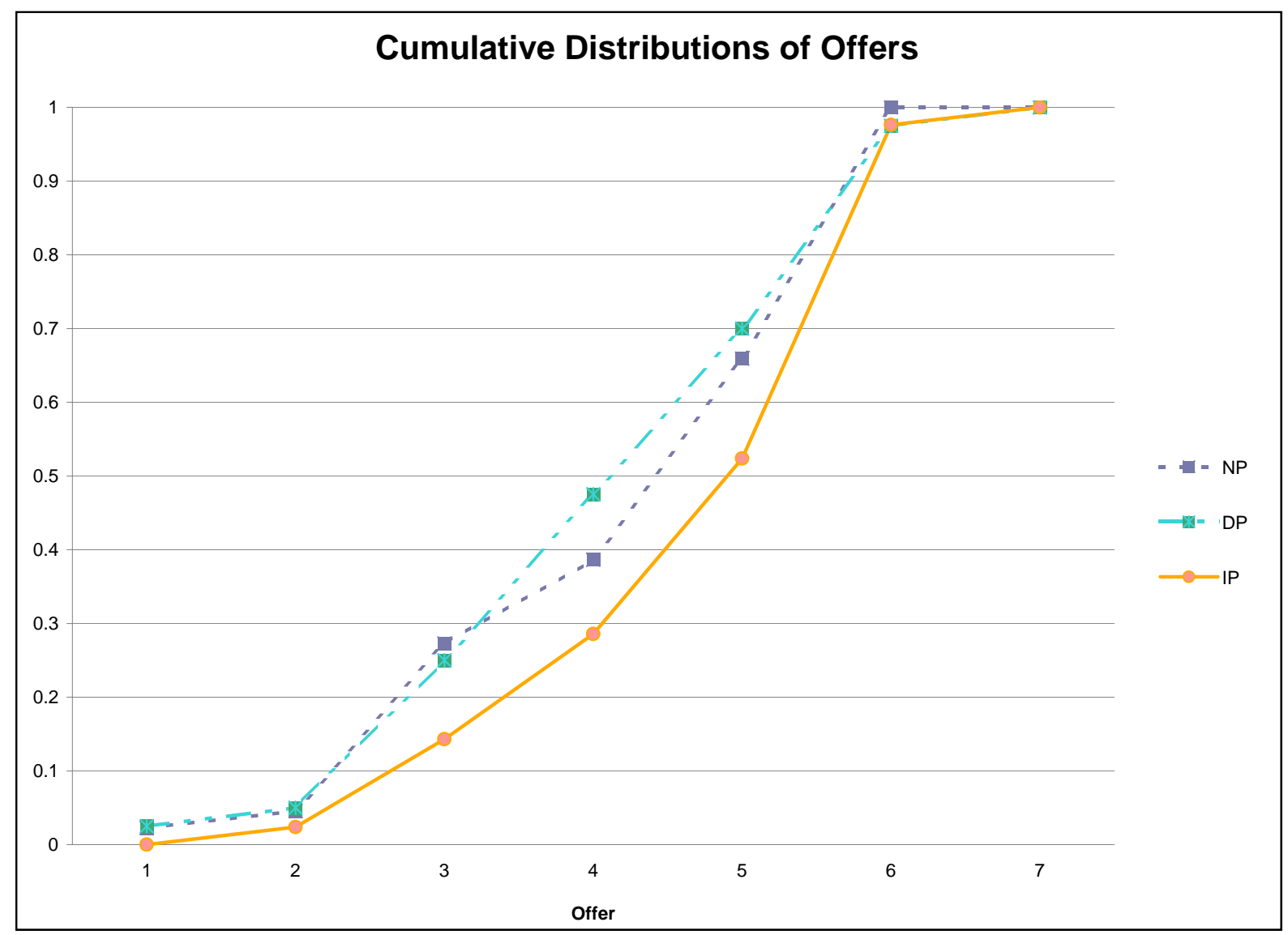

Figure 1: Cumulative Distributions of Offers, By Treatment

Table 3: P-Values Associated with Each Pairwise Comparison of Mean Offers, by Treatment

\begin{tabular}{|c|c|c|c|}
\hline & IP & DP & NP \\
\hline IP & - & 0.00 & 0.19 \\
\hline DP & & - & 0.04 \\
\hline NP & & & - \\
\hline
\end{tabular}




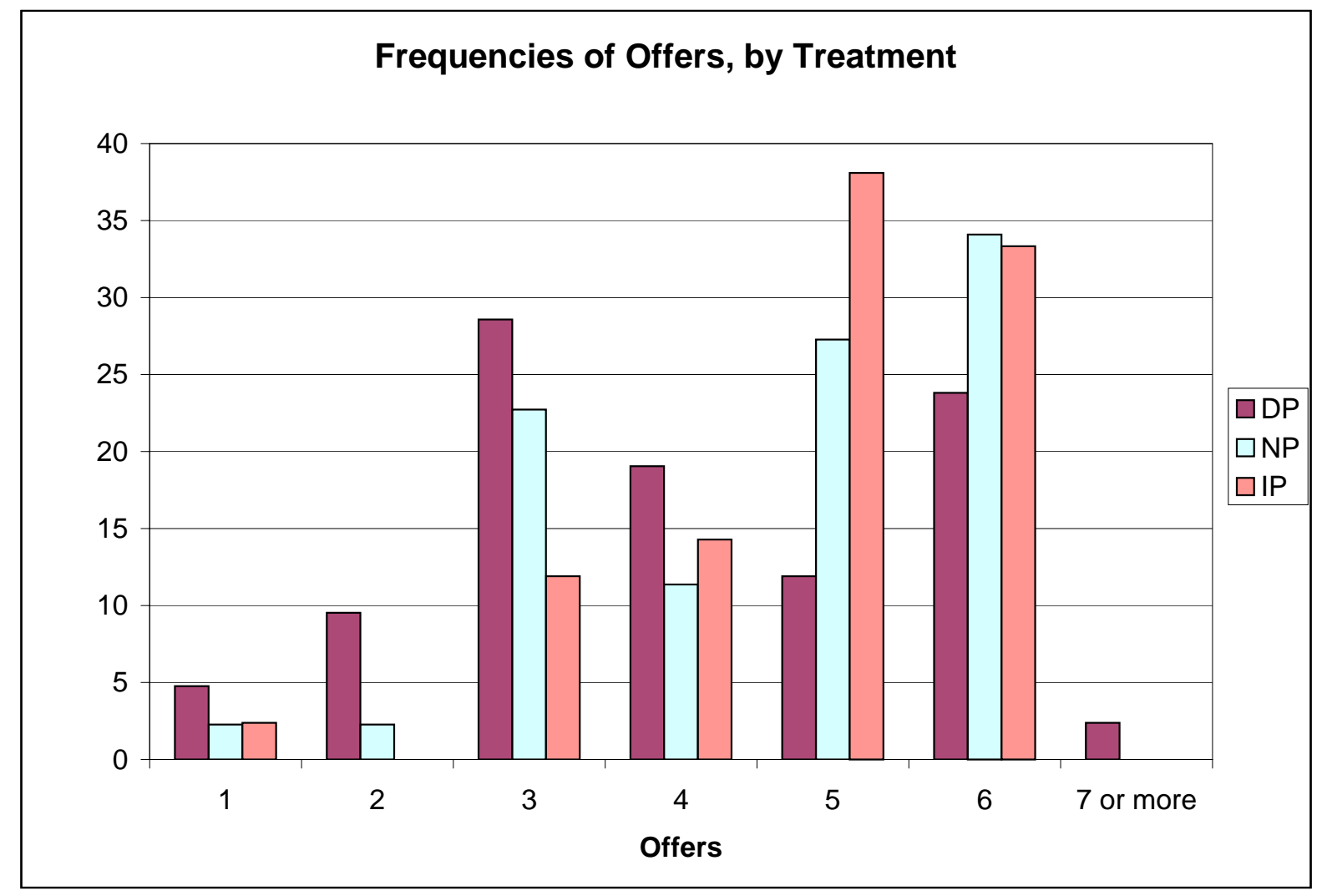

Figure 2: Frequencies of Offers, By Treatment 
treatment are in-between. Thus is appears that priming a shared identity increases demandingness amongst in-group pairs.

Table 4: Mean Minimum Acceptable Offers, by Treatment

\begin{tabular}{lcc}
\hline \hline Treatment & Mean MAO & Std. Err. \\
\hline & & \\
Identity-Prime & 3.00 & 1.41 \\
Distinctiveness-Prime & 2.40 & 1.43 \\
No-Prime & 2.61 & 1.48 \\
\hline
\end{tabular}

We conduct one-tailed $t$-tests to identify statistical differences in MAOs across treatments and report $p$-values from each pairwise test in Table 5 . We find that MAOs in the DP treatments are significantly lower than MAOs in the IP treatment. Interestingly, MAOs in the NP treatment are not significantly different from MAOs in any other treatment. Thus, participants were much more demanding (i.e. reported higher MAOs) in the IP treatment than in the DP treatment. It seems that while MAOs in the control treatment, NP, were in-between MAOs in the DP and IP treatments, the difference between NP and any other treatment was not large enough to result in statistical significance.

Table 5: P-Values Associated with Each Pairwise Comparison of Mean Minimum Acceptable Offers, by Treatment

\begin{tabular}{lccc}
\hline \hline & & & \\
& IP & DP & NP \\
\hline IP & - & $\mathbf{0 . 0 3}$ & 0.11 \\
DP & & - & 0.25 \\
NP & & & - \\
\hline
\end{tabular}

\section{Conclusion}

This paper is aimed at investigating the effect of identity salience on behavior in social interactions. Specifically, we conduct an experiment where we prime subjects to increase the salience of a shared identity or a distinct identity, and find that this 


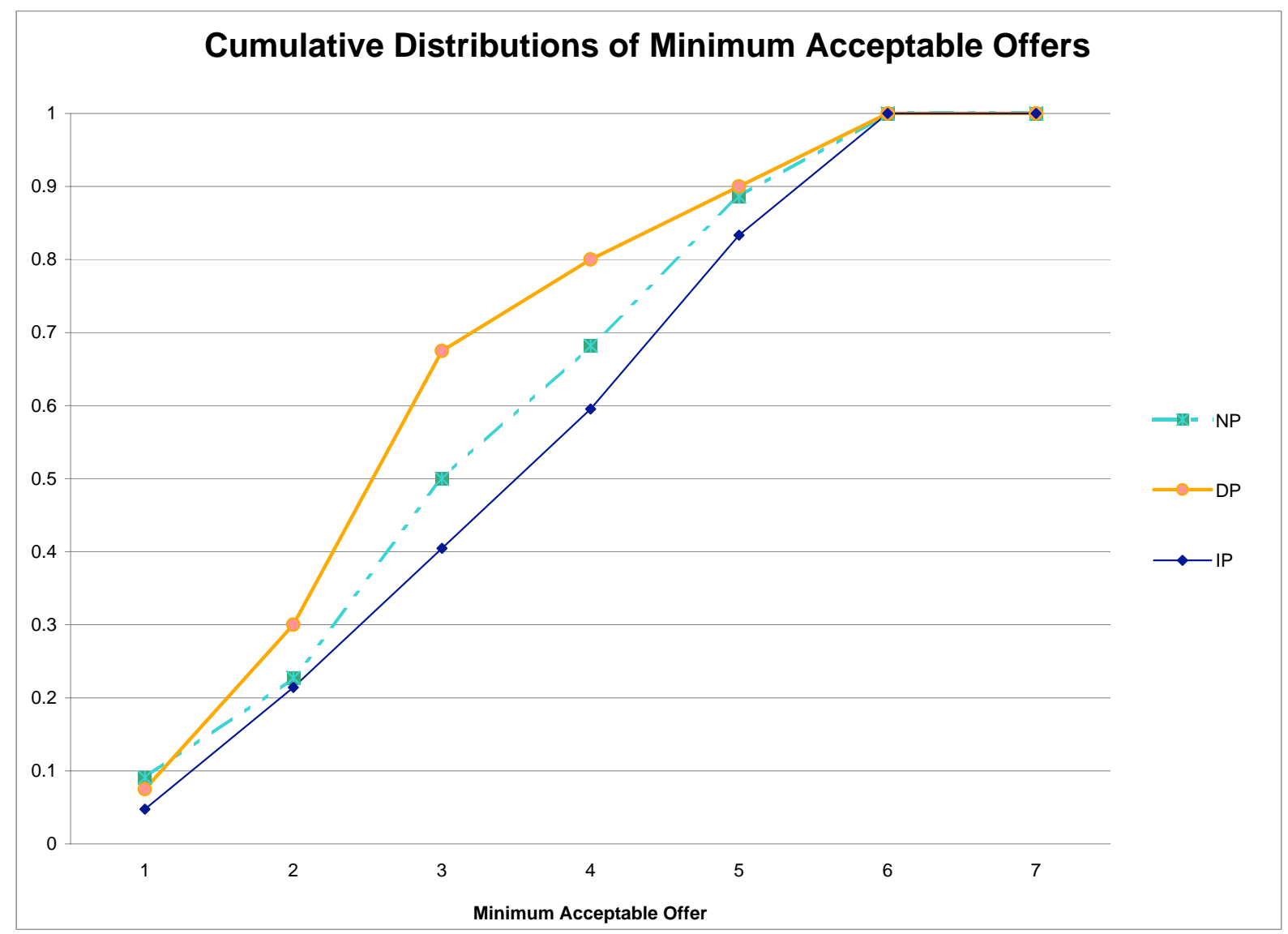

Figure 3: Cumulative Distributions of Minimum Acceptable Offers, By Treatment 


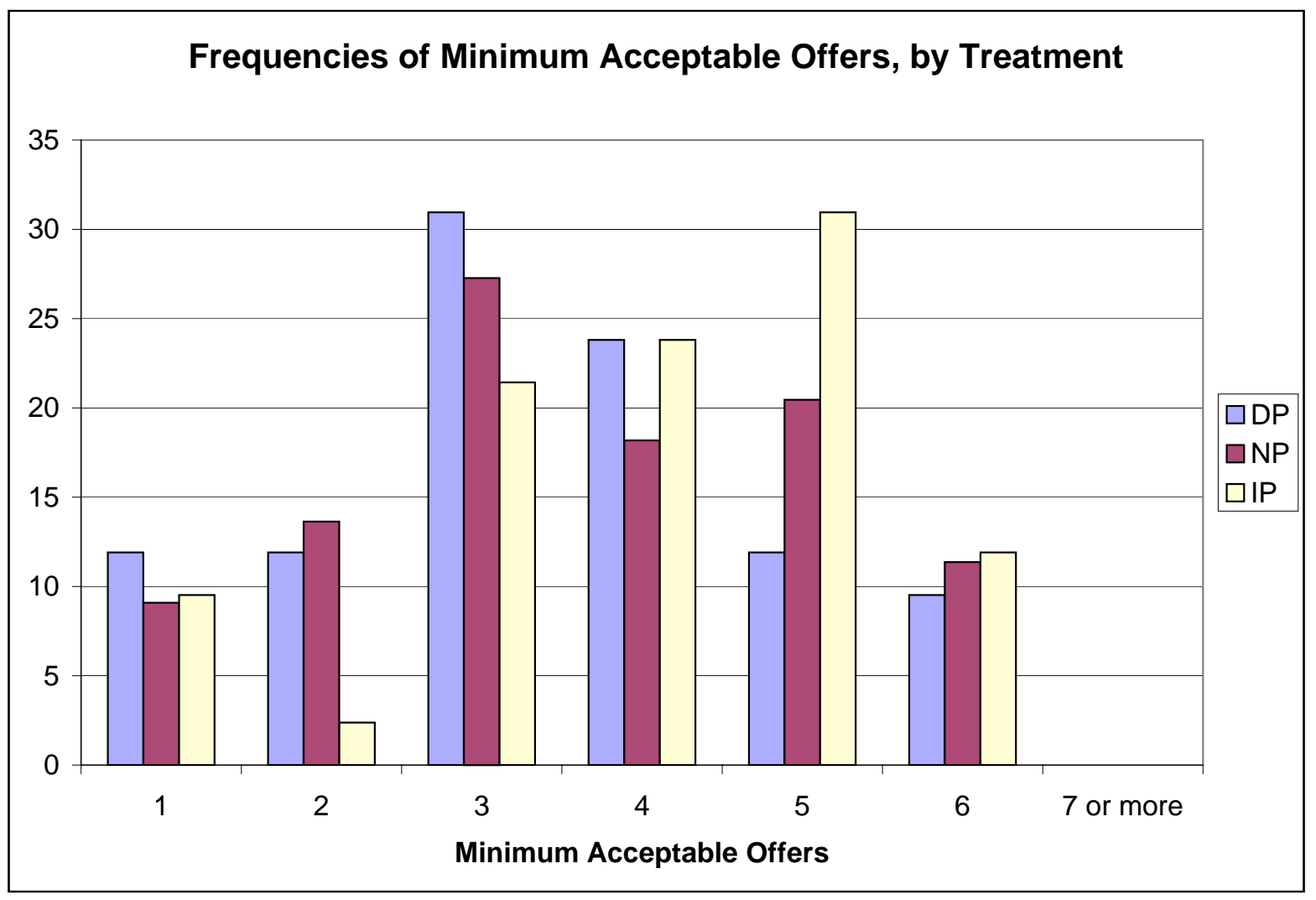

Figure 4: Frequencies of Minimum Acceptable Offers, By Treatment 
has a significant effect on behavior. Under particular circumstances, subjects primed with a shared identity are significantly more cooperative and more inclined toward negative reciprocity than subjects primed with a distinct identity.

The result that increasing the salience of identity increases cooperation may not be surprising, as manipulation of the salience of identity is often used in such arenas as politics, to gain support or to acquire backing for a political goal. ${ }^{7}$ The results are especially interesting if looked at in the context of labor negotiations and organizational design. Rabin (1997) discusses the importance of reciprocity in labor bargaining. Our results suggest that a shared identity among the parties to a negotiation may facilitate agreement through greater cooperation but, if one party views the other as behaving unfairly, may also generate greater demandingness, increasing the likelihood of a bargaining impasse. Similarly, increasing the salience of organizational identity among employees may involve a tradeoff between a greater tendency to cooperate and a greater tendency to engage in negative reciprocity (Akerlof and Kranton, 2005). This tendency towards negative reciprocity may be especially impactful during contract disputes, pushing potential outcomes towards inefficiency. It follows that a mediator wishing to avoid a nasty labor negotiation may with to downplay the salience of the employees' identification with the firm.

\footnotetext{
${ }^{7}$ For example, in order to bolster a defence for the Canadian health care system, proponents often emphasize the fact that it is "uniquely Canadian".
} 


\section{References}

Akerlof, G. A. and R. E. Kranton (2000). Economics and identity. Quarterly Journal of Economics 115(3), 715-758.

Akerlof, G. A. and R. E. Kranton (2004). Identity and schooling: Some lessons for the economics of education. Journal of Economic Literature 40(4), 1167-1201.

Akerlof, G. A. and R. E. Kranton (2005, Winter). Identity and the economics of organizations. Journal of Economic Perspectives 19(1), 9-32.

Alesina, A., R. Baqir, and W. Easterly (1999, November). Public goods and ethnic divisions. The Quarterly Journal of Economics 114(4), 1243-1284.

Alesina, A. and E. Ferrara (2000, August). Participation in heterogeneous communities. Quarterly Journal of Economics 115(3), 847-904.

Bargh, J. A., M. Chen, and L. Burrows (1996, August). Automaticity of social behavior: Direct effects of trait construct and stereotype activation on action. Journal of Personality and Social Psychology 71(2), 230-244.

Benabou, R. and J. Tirole (2006). Identity, dignity and taboos: Beliefs as assets. IZA Discussion Paper 2583.

Benjamin, D. J., J. J. Choi, and A. J. Strickland (2008). Social identity and preferences. Yale ICF Working Paper \#08-13.

Bernhard, H., E. Fehr, and U. Fischbacher (2006, May). Group affiliation and altruistic norm enforcement. American Economic Review 96(2), 217-221.

Camerer, C. F. (2003). Behavioral Game Theory. Princeton NJ: Princeton University Press.

Durlauf, S. (1999). The case against social capital. Focus 20(3), 1-4.

Dutton, J. E., J. M. Dukerich, and C. V. Harquail (1994, June). Organizational images and member identification. Administrative Science Quarterly 39(2).

Eckel, C. C. and P. J. Grossman (2005). Managing diversity by creating team identity. Journal of Economic Behavior and Organization 58, 371-392.

Fischbacher, U. (2007, June). z-Tree: Zurich toolbox for ready-made economic experiments. Experimental Economics 10(2), 171-178.

Gerber, G. (1998). Status in same-gender and mixed-gender police dyads: Effects on personality attributions. Social Psychology Quarterly 59, 350-363. 
Goette, L., D. Huffman, and S. Meier (2006). The impact of group membership on cooperation and norm enforcement: Evidence using random assignment to real social groups. Institute for Empirical Research in Economics.

Kramer, R. M., P. Pommerenke, and E. Newton (1993, December). The social context of negotiation: Effects of social identity and interpersonal accountability on negotiator decision making. Journal of Conflict Resolution 37(4), 633-655.

Mackie, D. M. (1986). Social identification effect in group polarization. Journal of Personality and Social Psychology 50(4), 720-728.

McLeish, K. N. and R. J. Oxoby (2007). Identity, cooperation, and punishment. IZA Discussion Paper 2572.

Oxoby, R. J. and K. N. McLeish (2004). Specific decision and strategy vector methods in ultimatum bargaining: Evidence on the strength of other-regarding behavior. Economics Letters 84(3), 399-405.

Rabin, M. (1997). Bargaining structure, fairness, and efficiency. University of Califoria, Berkeley, Working Paper.

Shih, M., N. Ambady, J. A. Richeson, K. Fujita, and H. M. Gray (2002). Stereotype performance boosts: The impact of self-relevance and manner of stereotype activation. Journal of Personality and Social Psychology 83(3), 638-647.

Shih, M., T. L. Pittinsky, and N. Ambady (1999, January). Stereotype susceptibility: Identity salience and shifts in quantitative performance. Psychological Science $10(1), 80-83$.

Solow, J. L. and N. Kirkwood (2002). Group identity and gender in public goods experiments. Journal of Economic Behavior and Orgainization 48, 403-412.

Spencer, S. J., C. M. Steele, and D. M. Quinn (1999). Stereotype threat and women's math performance. Journal of Experimental Social Psychology 35, 4-28.

Steele, C. M. and J. Aronson (1995). Stereotype threat and the intellectual test performance of African Americans. Journal of Personality and Social Psychology 69, 797-811.

Stroebe, K., H. F. Lodewijkx, and R. Spears (2005). Do unto others as they do unto you: Reciprocity and social identification as determinants of ingroup favoritism. Personality and Social Psychology Bulletin 31(6), 831-845.

Wann, D. L. and F. G. Grieve (2005). Biased evlautions of in-group and out-group spectator behavior at sporting events: The imporance of team identification and threats to social identity. Journal of Social Psychology 145(5), 531-545. 
Wit, A. P. and H. A. M. Wilke (1992). The effect of social categorization on cooperation in three types of social dilemmas. Journal of Economic Psycology 13, $135-151$.

Yopyk, D. J. A. and D. A. Prentice (2005). Am I an athlete or a student? Identity salience and stereotype threat in student-athletes. Basic and Applied Social Psychology 27(4), 329-336. 


\section{A Sample Instructions}

\section{Instructions}

This is an experiment in decision-making. During the experiment you will be asked to make a number of decisions, the outcomes of which may result in a monetary payoff. You will receive this payment in cash at the end of the experiment. This payment is considered both compensation for the time and the effort you put into making your decisions. Throughout the experiment, we ask you to refrain from speaking with one another; if you have any questions please raise your hand and someone will assist you.

In the first part of the experiment, you will be asked to write for 10 minutes about a recent positive experience in which you felt connected with other University of Calgary students. This may be an experience at a social event (e.g., a party), an academic assignment (e.g., a group project), or simply a pleasant interaction with other students. We would like you to write about this experience in detail, recalling how you felt before, during, and after the experience. Try to recall any problems you faced during the interaction and how you overcame them. Try to write about how this experience made you feel as a University of Calgary student.

Please write on the piece of paper provided. Notice there is no identifying information on the envelope. What you write about will remain completely confidential and can in no way be tied to you personally.

After the 10 minute writing period has ended, we would like you to put the piece of paper in the envelope provided and seal the envelope. The experimenter will then collect these envelopes and the reminder of the experiment will take place on the computers.

After you have completed this first portion of the experiment you will be asked a series of questions and randomly matched (by the computer) with another person. Eventually, the computer will assign one of you to the role of Proposer and one of you to the role of Responder in a game which will determine your payoff for the experiment. Before this random assignment is made, you must indicate what you would do if you were put in either role.

In the role of Proposer, you will be asked how much (out of a total of $\$ 10$ ) you wish to allocate to the other person. The amount of money that you keep for yourself will be $\$ 10$ minus your allocation to the other person. In the role of Responder, you must indicate for each possible amount allocated to you from the Proposer whether you would accept or reject such an offer. That is, for each possible offer between 0 and $\$ 10$, you must indicate whether or not you would accept this offer. Your payoff from the experiment will depend on these decisions.

After everyone has made these decision, the computer will randomly assign each

person the role of Proposer or Responder, and their corresponding choices will be implemented. That is, the person assigned the role of Proposer will have their offer 
extended to the Responder; the Responder will accept or reject the offer based on the choices made for the relevant amount of the offer. If you are assigned the role of Proposer, you will receive $\$ 10$ less the offer you extended if the Responder accepts that offer; if the Responder rejects the offer you extended, you will both receive nothing. If you are assigned the role of Responder, you will receive the offer extended by the Proposer if you indicated that you would accept that offer; if you indicated you would reject that offer you will both receive zero.

You will be informed of your payoff from the experiment and asked to complete a short questionnaire. After everyone has completed the questionnaire, you will receive your payment in cash. Once we have answered any questions, the experiment will begin.

\section{Warm-Up Exercises}

1. If you are assigned the role of Proposer and you indicated that you would allocate the other person $\$ 3$, how much will you receive if this offer is accepted? How much will you receive if this offer is rejected?

2. If you are assigned the role of Responder and are offered $\$ 4$, how much will you receive if you indicated that you would accept a $\$ 4$ offer? How much will you receive if you indicated that you would reject a $\$ 4$ offer? 